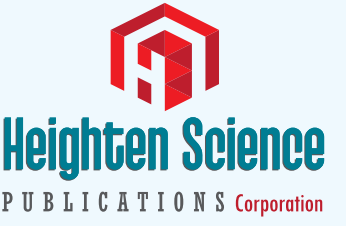

ISSN

2639-9911
*Address for Correspondence: Michael 0 Ogundele, Child Development Centre, Bridgewater Community Healthcare Foundation Trust, Warrington, UK, Email: m.ogundele@nhs.net

Submitted: 12 November 2016

Approved: 06 January 2017

Published: 08 January 2017

Copyright: @ 2017 Ogundele MO. This is an open access article distributed under the Creative Commons Attribution License, which permits unrestricted use, distribution, and reproduction in any medium, provided the original work is properly cited

Keywords: Professional multidisciplinary team members; The Multi-Professional team; Early intervention; High-Risk; Interdisciplinary

Check for updates

\section{A Multidisciplinary Approach to the Assessment and Management of Pre-school Age Neuro-developmental Disorders: A Local Experience}

\author{
Michael O Ogundele* \\ Child Development Centre, Bridgewater Community Healthcare Foundation Trust, Warrington, \\ UK
}

\section{ABSTRACT}

Background: Early and effective identification of childhood neurodevelopmental disorders remains a critical task of all pediatric healthcare professionals, which is critical to the well-being of children and their families.

Methods: A retrospective review of medical records of all preschool children referred to a Child Development Centre (CDC) in North-West England, over a six-month period between Sept 2014 and Feb 2015 was conducted. The local multi-professional approach to the clinical assessment and management of preschool children was described and the published literature on this topic was reviewed.

Results: Twenty four different categories of professionals spanning the whole range of primary, secondary, and tertiary healthcare, social care and educational services were involved in the management of the patients. The largest group of professionals was the primary healthcare specialists. The ten different primary care professionals managed an average of $42 \%$ of the patients.

The secondary healthcare providers were involved in the care of an average of $17 \%$, tertiary care providers $10 \%$, educational specialists $25 \%$ and social care professionals were involved with $5 \%$ of all the patients.

The commonest diagnostic disorders were Speech/Language delay (56\%), Global developmental delay (33\%), Behavior difficulties (26\%), Social communication concerns (21\%) and Autistic spectrum disorder (19\%).

Conclusion: The high number and specialties of various healthcare professionals at all levels of care indicates the high social and economic investment required in managing the affected preschool children in the region. Childhood neurodevelopmental disorders in the preschool age represents a high level of public health significance.

\section{INTRODUCTION}

Children with developmental difficulties constitute between $5 \%$ and $15 \%$ globally among general pediatric population [1,2]. Neuro developmental problems in preschool children are common and can have long-term adverse consequences if not detected and treated early. The preschool is a critical period for development and there is convincing evidence that early identification of developmental problems can result in better outcomes for the affected children and their families [3,4].

Timely and periodic assessment of young children's development makes it possible to identify and treat developmental disabilities at the earliest possible point of manifestation and to prevent loss of developmental potential. It can also help to identify developmental risk factors and target effective anticipatory guidance to 
provide parents with strategies for promoting optimal developmental outcomes [5]. Accurate early recognition and management of neuro-developmental delay present with unique challenges for several practitioner at several different levels, but is critical to the well-being of children and their families [6] and is a central precondition to their correct evaluation and management. Clinicians should encourage parents to participate in early intervention programs, because high-quality maternal interactive behaviors are known to be correlated with improved developmental outcomes in developmentally delayed children [7].

A common approach to early identification of neurodevelopmental disorders to ensure optimal intervention and limitation of secondary disabilities is developmental surveillance. Screening as part of surveillance programme takes place at different specified times and in different places including delivery points, home visits by accredited professionals, special children centers and at schools. In the United Kingdom, every child from birth to the age of 5 years benefits from the Healthy Child Programme (HCP), which incorporates preventative and health promotion strategies for ensuring the health and wellbeing of children in England. One of the HCP's core functions is to recognize disability and developmental delay, to ensure that children receive appropriate referral to specialist services, and families are signposted to wider support services. It provides an invaluable opportunity for screening tests and developmental surveillance, assessing growth, identifying social and emotional risk factors, providing additional ongoing support to families that are in need of emotional and social support and to children who are at risk of poor outcomes [8].

Developmental assessment programs benefit from the involvement of a wide variety of professionals who are part of a multi-disciplinary team, each suitably skilled and prepared to meet the needs of the children and their families. Multidisciplinary and inter-professional approach has been documented to be effective in the management of many childhood situations spanning from healthy child surveillance to inpatient mental health care $[9,10]$. The primary care provides a unique area of potential ample opportunities for training and promotion of high-quality developmental surveillance [11].

Developmental or neuro-behavioral Pediatricians constitute the lead professionals involved in the care and management of children and adolescents with neurodevelopmental disorders. Assessment, investigation, and consultation with the family are part of the prime responsibility of the Pediatricians, in collaboration with a multidisciplinary team, including a thoughtful assessment of the child and family needs [12]. Neuro-behavioral Pediatricians (NBP) with care of children who have problems of biological origin, presumed if not demonstrated, that impact on the child's development and/or behavior. It involves a complex interplay of not only individual child but also their social systems and context, involvement of multidisciplinary services including physical and mental health, social and justice services [13].

There is wide variation in the timing of developmental milestones from child to child, but every child develops continuously according to his or her own pattern. Specific developmental disorders such as dyslexia, attention-deficit hyperactivity disorder, autistic spectrum disorder and auditory processing disorders (APD) often co-occurs with impairments of language, literacy, and attention. Each child often requires a multi-professional approach to the diagnosis and management. It is essential to ensure that children have access to the most appropriate range of support and interventions [14]. Many categories of professionals are often involved, including therapists (Speech and language, Occupational therapists), psychology and mental health professionals, Pediatricians, primary care professionals including nurses, social care professionals, allied healthcare professionals (e.g. Audiology/Vestibuloauditory), educational staff including Educational Psychologist, Early-years practitioners, and nursery nurses $[15,11]$. 


\section{METHODS AND DESIGN}

We describe the multi-professional inter-disciplinary approach to the management of preschool children presenting with various neuro-developmental disorders at a Child Development Centre (CDC) of a North West of England Local Authority. A retrospective review of medical records of all the cases referred to CDC over a six-month period between Sept 2014 and Feb 2015 was conducted. Standardized demographic and referral information were collected, including source and age at referral, details of clinical diagnosis, follow-up duration, clinic attendance and discharge. Analysis was conducted on the range of clinical diagnosis, the multidisciplinary professionals involved, duration and schedule of follow-up.

The audit was completed as part of the Clinical Governance strategies of the Bridgewater Community Healthcare Foundation Trust. It was conducted as part of a service audit of the preschool workload in the Trust. No identifiable patient record was used and no research ethical approval was required.

Statistical analysis included Spearman Rank Correlation coefficient (Wessa, 2012), Spearman Rank Correlation (v1.0.1) in Free Statistics Software (v1.1.23-r7), Office for Research Development and Education, URL http://www.wessa.net/rwasp_spearman. wasp/) and Student's T test to compare percentages or mean from two independent samples (http://www.graphpad.com/quickcalcs/ttest1/?Format=SD).

We also carried out a literature review relating to the multidisciplinary management approach of neuro-developmental disorders in preschool children. We performed a comprehensive search of Medline, EMBASE, CINAHL and Cochrane databases. No quantitative synthesis (meta-analysis) was deemed appropriate because of the quantitative design of most studies and the wide variability in the design, types of studies, interventions and outcomes of the literature.

\section{RESULTS}

\section{Local population and Service description}

Warrington is a medium-sized Local Authority Borough with a total adult and children population of 205,150 (mid-year estimate from 2013), $6 \%(12,519)$ are aged $0-4$ yrs. and 36,280 are aged 5-19 yrs. There are estimated 2366 live births annually in the local borough.

The Child Development Centre (CDC) is the secondary referral centre, providing therapeutic and preventative community pediatric care for all pre-school children from 0 to 5 years of age with any neuro-developmental or behavioral difficulties. The CDC accepts referrals from a wide variety of primary care practitioners, allied medical healthcare professionals, school and nursery staff. Each new referral is discussed by a multi-disciplinary group of practitioners within the "Complex case" panel, which meets weekly. After the patient has been considered as an appropriate referral, the family is contacted by a specialist nurse from the CDC to carry out a preliminary assessment and obtain detailed information about the family, provide information about the service and preliminary advice about behavioral difficulties.

The CDC has a direct link with the local secondary care District General Hospital (DGH) and a tertiary children's hospital for access to laboratory pathology and radiological investigation services and for tertiary specialist expertise. Each patient is assessed and followed up by a Consultant or a senior Community Pediatrician.

\section{Epidemiological characteristics}

A total of 118 patients were seen during 120 clinical encounters during the six -month period. This is equivalent to 100 case per 1000 live births per year .Age of 
patients ranged from 8 to 69 months (mean 42.3). Age at referral was between 2 and 58 months (mean 28.6) with mean duration of follow-up for 13.5 months. Each patient had a mean of 6 multi-disciplinary professionals involved in their care with an average of 3 specific neurodevelopmental diagnoses. 26 patients were newly referred at mean age of 38 months (compared to 26 months in older referrals). 13 children were discharged at mean age of 46 months. Those discharged were older (46 vs 42 months) and referred later (at 35 vs 28 months) with shorter follow-up duration (7.5 vs 11 months) than others (Table 1).

\section{Range of clinical diagnosis}

Over 29 categories of ND diagnoses were identified (Table 2). The commonest diagnostic conditions were Speech/Language delay (SALD) (56\%), Global developmental delay (GDD) (33\%), Behavior difficulties (26\%), Social communication (SC) concerns (21\%) and Autistic spectrum disorder (ASD) (19\%). 15\% were born prematurely, $12 \%$ had specific genetic syndrome other than Down's, while $11 \%$ had congenital defects and motor delay. The diagnosed genetic syndromes included Angelman's (1), West (1), Fragile X (1), partial Patau's (1), Dravet's (1), Sturge Weber (1), Beckwith-Wiederman (1) and Gomez-Lopez-Hernandez (1). There was a child with Trisomy 8 and 3 children with genetic duplications or deletions on chromosomal array test. The congenital defects diagnosed included biliary atresia, intestinal atresia, microphthalmia, colobomata, microcephaly, craniosynostosis and Pierre-Robin sequence.

Three patients each were diagnosed with iron deficiency, and sensory integration difficulties. Other surgical diagnoses included Hernias (2), VP shunt (2) and undescended testis (1). Other preterm related diagnoses were CLD (1), slow growth (1) and Plagiocephaly (2).

Each child had one to seven distinct diagnoses (mean of 3 ) and there was a correlation (Figure 1) between the number of diagnosed conditions and the average number of professionals involved (from 4.7 for 1 or 2 problems to 9.3 for those with 7 diagnoses).

\section{Multidisciplinary professionals}

Twenty four different categories of professionals spanning the whole range of primary, secondary, and tertiary healthcare, social care and educational services were involved in the management of the patients (Table 3). The largest group of professionals involved were the primary healthcare specialists. The ten different primary care professionals managed an average of $42 \%$ of the patients. The secondary healthcare providers were involved in the care of an average of $17 \%$, tertiary care providers $10 \%$, educational specialists $25 \%$ and social care professionals were involved with $5 \%$ of all the patients.

The most commonly involved professionals were the Health Visitors (HV) (100\%), Speech/Language Therapists (SALT) (94\%), Audiologists (68\%), Early-

Table 1: Comparing characteristics of patients discharged and those on current caseload.

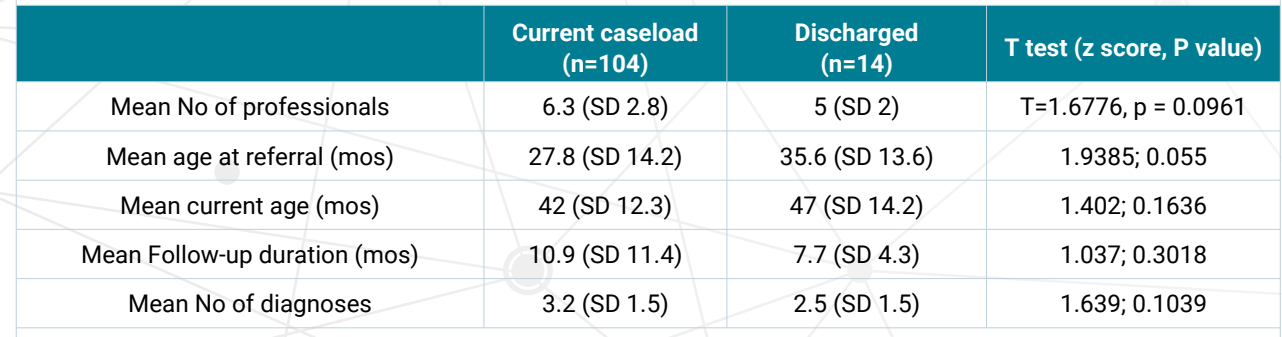

SD: Standard Deviation; Mos: Months 
Table 2: showing list of diagnosis and average number of professionals involved.

\begin{tabular}{|c|c|c|c|}
\hline Diagnosis & No_Pts & Percent & Avg_Prof \\
\hline SALD & 66 & 55.93 & 5.48 \\
\hline GDD & 39 & 33.05 & 7.4 \\
\hline Behav_Diff & 30 & 25.42 & 4.67 \\
\hline SC_Concern & 25 & 21.19 & 4.4 \\
\hline ASD & 22 & 18.64 & 5.09 \\
\hline Ex_Prem & 17 & 14.41 & 8.29 \\
\hline Genetic $*$ & 14 & 11.86 & 9.36 \\
\hline Motor_Delay & 13 & 11.02 & 7.69 \\
\hline Cong_Defect & 13 & 11.02 & 8.9 \\
\hline Visual_Impaired & 10 & 8.47 & 8.6 \\
\hline Feeding/GOR & 10 & 8.47 & 8 \\
\hline Sleep_Diff & 9 & 7.63 & 6 \\
\hline $\mathrm{CHD}$ & 9 & 7.63 & 9.56 \\
\hline Orthopaedic & 8 & 6.78 & 9.4 \\
\hline Hypotonia & 8 & 6.78 & 10.4 \\
\hline $\mathrm{CP}$ & 7 & 5.93 & 7.86 \\
\hline Hydrocephalus $^{\beta}$ & 7 & 5.93 & 8.57 \\
\hline Hearing_Impaired & 6 & 5.08 & 9.3 \\
\hline IVH_HIE & 6 & 5.08 & 6.67 \\
\hline LD & 5 & 4.24 & 6.8 \\
\hline Epilepsy & 5 & 4.24 & 6.8 \\
\hline Downs & 5 & 4.24 & 9.2 \\
\hline DCD & 4 & 3.39 & 5.5 \\
\hline Spinal_Bifida & 3 & 2.54 & 5.3 \\
\hline Hypermobility & 3 & 2.54 & 6.3 \\
\hline Drooling & 2 & 1.69 & 9 \\
\hline
\end{tabular}

SALD - Speech and Language delay; GDD - Global Developmental Delay; Behav - Behaviour; Diff - Difficulties; SC - Social communications; ASD - Autistic Spectrum Disorder; Cong - Congenital; CHD - Congenital Heart diseases; CP - Cerebral Palsy; IVH - Intraventricular haemorrhage; HIE - Hypoxic-Ischaemic Encephalopathy; LD - Learning Difficulties; DCD - Developmental Coordination Disorder

* Genetic syndromes including Angelman's

${ }^{\beta}$ Including Arnold Chiari malformation

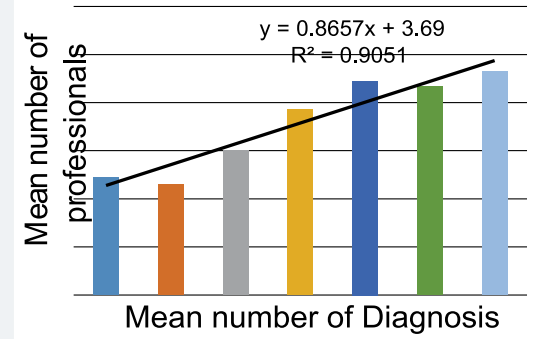

Figure 1: The average number of professionals involved based on the number of Neurodevelopmental diagnosis in each patient.

Spearman correlation coefficient rho $0.9285 ; 2$-sided $p$-value $=0.0067$

Years Educational Consultants (EY-EC) (54\%), Physiotherapists (44\%), Occupational Therapists (OT) (37\%), General Paediatricians (32\%), Specialist Nurses(32\%), Orthoptist (28\%) and Educational Psychologists (15\%). Other Secondary healthcare professionals included the surgeons: orthopaedic $(12 \%)$ ENT $(10 \%)$ and ophthalmogists (9\%). Tertiary specialists' involvement included Neurologists (16\%), Geneticists (15\%), Cardiologists (8\%) and Neurosurgeons (7\%).

Other professionals involved in a minority of patients were Cleft palate team (1), 
Table 3: Showing categories of professionals at different healthcare levels involved. Professionals

\section{No_Pts}

\begin{tabular}{|c|c|c|c|}
\hline \multirow{10}{*}{$\begin{array}{l}\text { Primary Care } \\
\text { Mean }=41.8 \%\end{array}$} & HIt Visitor & 118 & 100 \\
\hline & SALT & 111 & 94.1 \\
\hline & Audiology & 80 & 67.8 \\
\hline & Physio & 51 & 43.2 \\
\hline & OT & 43 & 36.4 \\
\hline & Spec_Nurse & 37 & 31.4 \\
\hline & Orthoptist & 34 & 28.8 \\
\hline & Dietitian & 12 & 10.2 \\
\hline & Continence Serv & 6 & 5.1 \\
\hline & Sch_Nurse & 1 & 0.8 \\
\hline \multirow{3}{*}{$\begin{array}{l}\text { Secondary Care } \\
\text { Mean }=17.3 \%\end{array}$} & Gen_Paed & 37 & 31.4 \\
\hline & Ortho_Surg & 14 & 11.9 \\
\hline & Ophthalmol & 10 & 8.5 \\
\hline \multirow{6}{*}{$\begin{array}{l}\text { Tertiary Care } \\
\text { Mean }=9.7 \%\end{array}$} & Neurologist & 19 & 16.1 \\
\hline & Geneticist & 17 & 14.4 \\
\hline & ENT & 11 & 9.3 \\
\hline & Cardiologist & 9 & 7.6 \\
\hline & Neurosurgeon & 8 & 6.8 \\
\hline & Gastro & 5 & 4.2 \\
\hline \multirow{3}{*}{$\begin{array}{l}\text { Education Specialists } \\
\quad \text { Mean }=25 \%\end{array}$} & EY_SEN & 63 & 53.4 \\
\hline & Educ_Psych & 18 & 15.3 \\
\hline & Sp_Teachers & 7 & 5.9 \\
\hline Social care & Social Worker & 9 & 7.6 \\
\hline Mean $=5 \%$ & FSW & 3 & 2.5 \\
\hline
\end{tabular}

SALT: Speech and Language Therapist; EY-SEN: Early Years Special Education Needs Coordinator/ Consultant; OT: Occupational Therapist; ENT: Ear, Nose, Throat surgeon; FSW: Family Support Worker

Table 4: Showing examples of preschool disorders requiring multidisciplinary professional approach.

\begin{tabular}{|c|c|c|}
\hline Specialty & Specific conditions & Literature \\
\hline \multirow[t]{5}{*}{ Neurodevelopment } & ASD Diagnosis and management & {$[42,38,37]$} \\
\hline & Learning and behavioural problems & [43] \\
\hline & Language-impairment & [44] \\
\hline & Cerebral Palsy & {$[45,46]$} \\
\hline & Developmental Surveillance & [47] \\
\hline \multirow[t]{2}{*}{ Respiratory } & Asthma & [48] \\
\hline & infants with chronic lung disease & [49] \\
\hline \multirow[t]{4}{*}{ Neurology } & Spinal Muscular Atropy (SMA) & {$[50]$} \\
\hline & Traumatic brain injury & [51] \\
\hline & Epilepsy & [52] \\
\hline & Neurocritical care & [32] \\
\hline Nutritional & Obesity & {$[53,54]$} \\
\hline \multirow[t]{2}{*}{ Health Services } & Transitioning & [55] \\
\hline & Minimizing drug errors & [55] \\
\hline Genetic & Beckwith-Wiedeman syndrome & {$[57]$} \\
\hline & Haemophilia & [58] \\
\hline Mental Health & Eating disorders in children and adolescents. & [59] \\
\hline Surgical & Cleft lip/palate & {$[60,61]$} \\
\hline & Complex head trauma & [62] \\
\hline & Hirschsprung's disease & [63] \\
\hline & Spinal bifida & [64] \\
\hline & Congenital Heart Diseases & [65] \\
\hline Rheumatology- & Fibromyalgia & {$[66,67]$} \\
\hline \multirow[t]{2}{*}{ Endocrine disorders } & Cushing syndrome, & [68] \\
\hline & Craniopharyngioma & [58] \\
\hline Metabolic disorders & Mucopolysaccharidosis (MPS) & [10] \\
\hline
\end{tabular}


Clinical Psychologist (1), Nephrologist (1), Podiatrist (1), Urologist (1), Plastic surgeon (1), Neurophysicist (1).

There was a clear relationship relationship between the number of neurodevelopmental diagnosis in each patient and the mean number of multi-disciplinary professionals involved in their management (Figure 1). The Spearman Rank order Correlation coefficient $(r=0.93$. $p$ value $=0.00)$.

\section{Literature Review}

A critical review of the literature identified a need for an integrated multidisciplinary effort by healthcare providers and other stakeholders at different levels for the management of a wide range of preschool diseases and neuro-developmental disorders. Table 4 includes a list of common medical and surgical clinical conditions for which multi-professional working is indispensable.

\section{DISCUSSION}

A similar range of neurodevelopmental disorders have been found in similar CDC settings worldwide with involvement of multidisciplinary teams including developmental therapists, speech therapists, preschool teachers, special educators, clinical child psychologists and developmental pediatricians [16]. Previous studies of children with NDD have shown marked male preponderance (166/224), especially among those with either cognitive or language delay $[17,18]$.

Speech and language delay is one of the commonest NDD in preschool children in most populations [16]. The outpatient consultation for a child with speech and language delay often requires a multidisciplinary approach and should consist of a structured history, examination, and relevant targeted investigations with the aim of identifying whether the delay is primary or secondary in nature,. lead to a correct diagnosis of the delay and enable appropriate treatment. It also requires full cooperation from the child's parents [19].

Preschool neurodevelopmental disorders often affect multiple inter-related areas and co-morbid or co-occurring disabilities are often the norm rather that the exemption $[18,17,20]$. The need for effective and comprehensive services and efficiency within interdisciplinary teams is therefore oftentimes paramount. Autistic Spectrum Disorder (ASD) is one of the other common and significantly debilitating neuro-behavioral disorders manifesting from preschool age. The combination of symptoms of Attention Deficit Disorder (ADHD) and ASD in the same children is common and a number of overlapping co-morbidities have been reported. Children with the combined symptoms tend to have a lower IQ mean, a higher autistic symptoms severity and will tend to present very early in preschool age [21]. Most of the parents and the teachers of children with suspected ASD, have their first concern about the child's development before the child's second birthday [22]. Improved long-term outcome in children with ASD has been related to earlier parental concern, earlier referrals to specialists, and earlier and more intensive interventions [23].

Surgical professionals including the Otolaryngologist play a key role in the multidisciplinary management of individuals with ND disorders such as ASD, Auditory processing disorder (APD) and Downs Syndrome, due to the high prevalence of otological pathology amongst these patients [20]. ASD patients have a higher incidence of profound sensorineural hearing loss, middle ear infections, and abnormalities of the cochlear nerve and brainstem auditory pathways. There are cortical and brainstem neurodevelopmental abnormalities in the way auditory information is interpreted and processed in the ASD patient [20]. 
Many children or adolescents with ASDs also have sensory abnormalities, neurological disorders and additional disabilities of vision, hearing or ambulation and psychiatric co-morbidities. Diagnostics and rehabilitation are therefore best implemented in an integrated multi-professional setting [24].

Many carers of preschool children with neurodevelopmental disorders may also benefit from the support and professional advice from multidisciplinary staff. Caring for a child with disability can be exhausting and stressful, and social support for the parents is an important coping resource. Compared with other parents, mothers of children with autism spectrum disorder or other neurodevelopmental disabilities have unmet mental health needs as they experience more stress, illness, and psychiatric problems [25].

Multidisciplinary teams with interdisciplinary approach and holistic integrated services for assessment of developmental delays have been established in a number of countries including India, Finland, Sweden and the UK [26-28,8]. This approach ensures a healthy dynamic future for all children. Multidisciplinary professional team (MDT) approaches are already the standard mechanism for delivering mental health care and other chronic diseases such as cancer in several settings, including health care professionals, policy-makers and patient representatives [29].

The imperative of integrated multidisciplinary professional working with children and adolescents has been a recognized priority for a long time in the UK. The evolving of the model provides an interesting study. The 2004 Children Act saw the introduction of integrated working in children's services, directing professionals to work together for the benefit of children, young people and families. This led to new complexity of practical and personal difficulties as professionals endeavored to work together in new ways [30]. Currently there are two million workers in the children's workforce [31] trained in 60 separate professions that constitute the thirteen sectors of the 'children's workforce' in the UK. Some are located together geographically, others remain geographically separate but still work jointly, some share goals, and others pool budgets, so there are many contextualized forms of the deceptively simple term 'integration'.

The aim of integrated working was to ensure that no children fell through the gaps between services, and to reduce duplication of work by multiple services in a culture of increasingly high stakes accountability. A number of tools were mandated that allegedly facilitated integrated working such as the 'common assessment framework', the role of the 'lead professional', a data base of information available to all services called 'contact point' and 'information sharing' protocols [30].

Preschool developmental surveillance programs need to be holistically structured in order to be effective. Inter-professional collaboration is an important aspect of successful developmental intervention therapies.

Advantages of inter-disciplinary cooperation among multi-professional teams have been well documented in several pediatric, medical and surgical conditions, including reduced length of hospital admission and improved quality of life [31-33]. Multidisciplinary regular early intervention among Down syndrome children have been shown to significantly improve rates of school attendance compared to others not receiving regular early interventions [34]. Early diagnosis and expedient treatment of co-morbidities such as normalization of auditory input and development can maximize developmental outcomes [20].

The roles of inter-disciplinary working in improving outcomes in preschool neurodevelopmental disorders have not been extensively studied. Multidisciplinary working among preschool children have been shown to effectively provide optimal 
support to both client families and care providers including significant reduction in waiting times, improved attendance at therapy sessions, despite an increasing case load, through more efficient utilization of time and resources [35]. It appears to lead to earlier detection of ASD [36]. A multidisciplinary approach to treatment is recommended due to the impact of autism on many aspects of behavior and development $[37,38]$

Acomprehensivemedicalevaluationisessentialforidentifyingtheunderlyingetiology and risk factors for the NDD and may include brain imaging, electroencephalogram (EEG), genetic testing, and/or metabolic testing [39]. Identification of an etiology may provide parents with a greater depth of understanding of their child's disability, assist with various aspects of treatment planning, including specific prognostic information, genetic counseling around recurrence risk and family planning, specific medical treatments for improved health and function of the child, and therapeutic intervention programming [40]. An underlying etiology will be identified in approximately one quarter of cases of delayed development, with higher rates (>50\%) in children with global developmental delays and motor delays and lower rates $(<5 \%)$ in children with isolated language disorders [41].

\section{LIMITATIONS}

This study was a single center service audit describing an integrated multiprofessional inter-disciplinary model of working with preschool children presenting with various neuro-developmental disorders. It may be similar but not necessarily replicable in other healthcare centres across the UK and worldwide. It gives some insight into the range and multiplicity of professionals involved in the assessment and management of developmental disorders in preschool age children.

\section{CONCLUSION}

Optimal management and follow-up of preschool children with neurodevelopmental (ND) disorders involves several multidisciplinary professionals (MDP), whose activities are best coordinated if they are co-located within the same or nearby offices such as the CDC.

The high proportion of preschool children referred to the CDC with various degrees of neurodevelopmental disorders confirms its important public health significance. The high number and specialties of various healthcare professionals at all levels of care indicates the high social and economic investment required in managing the affected preschool children in the region.

\section{REFERENCES}

1. Glascoe FP. Early detection of developmental and behavioral problems. Pediatr Rev. 2000; 21: 272279. Ref.: https://goo.gl/PYsOjY

2. Demirci $A$, Kartal $M$. The prevalence of developmental delay among children aged 3-60 months in Izmir, Turkey. Child Care Health Dev. 2015; 42: 213-219. Ref.: https://goo.gl/IGcxg6

3. Bennett FC, Guralnick MJ. Effectiveness of developmental intervention in the first five years of life. Pediatr Clin North Am. 1991; 38: 1513-1528. Ref.: https://goo.gl/6xiqNE

4. Shonkoff JP, Phillips DA. From Neurons to Neighborhoods: The Science of Early Childhood Development. National Research Council and Institute of Medicine. Washington, DC: National Academy Press. 2000; Ref.: https://goo.gl/SrSmaH

5. Regalado $\mathrm{M}$, Halfon N. Primary care services promoting optimal child development from birth to age 3 years: review of the literature. Arch Pediatr Adolesc Med. 2001; 155: 1311-1322. Ref.: https://goo.gl/PDTwle

6. Council on Children with Disabilities: Section on Developmental Behavioral Pediatrics. Bright Futures Steering Committee and Medical Home Initiatives for Children with Special Needs Project Advisory Committee. Identifying infants and young children with developmental disorders in the medical home. Pediatrics. 2006; 118: 405-420.Ref.: https://goo.gl/DJgWWy

7. Wang PJ, Morgan GA, Hwang AW, Chen LC, Liao HF. Do maternal interactive behaviors correlate with 
developmental outcomes and mastery motivation in toddlers with and without motor delay? Phys Ther. 2014; 94: 1744-1754.Ref.: https://goo.gl/VeVoYZ

8. Department of Health (UK). Healthy Child Programme - Pregnancy and the first five years. Crown Copyright. 2009; Ref.: https://bit.ly/2FSCiih

9. Smith L, Strümpher J, Morton DG. Perceptions of mental healthcare professionals regarding inpatient therapy programmes for adolescents in the Eastern Cape, South Africa. J Child Adolesc Ment Health. 2015; 27: 59-73. Ref.: https://goo.gl/r0y1rV

10. Choy YS, Bhattacharya K, Balasubramaniam S, Fietz M, Fu A, et al. Identifying the need for a multidisciplinary approach for early recognition of mucopolysaccharidosis VI (MPS VI). Mol Genet Metab. 2015; 115: 41-47. Ref.: https://goo.gl/hFIUV4

11. Woolfenden S, Short K, Blackmore R, Pennock R, Moore M. How do primary health-care practitioners identify and manage communication impairments in preschool children? Aust J Prim Health. 2015; 21: 176-181. Ref.: https://goo.gl/pu57vh

12. Tirosh E, Jaffe M. Global developmental delay and mental retardation--a pediatric perspective. Dev Disabil Res Rev. 2011; 17: 85-92. Ref.: https://goo.gl/fnzh9q

13. McDowell M. Neurodevelopmental and behavioural paediatrics. J Paediatr Child Health. 2015; 51 113-117. Ref.: https://goo.gl/4EevJ5

14. Witton C. Childhood auditory processing disorder as a developmental disorder:the case for a multi-professional approach to diagnosis and management. Int J Audiol. 2010; 49: 83-87. Ref.: https://goo.gl/3sztfm

15. Lynch BA, Weaver AL, Starr SR, Ytterberg KL, Rostad PV, et al. Developmental Screening and Followup by Nurses. MCN Am J Matern Child Nurs. 2015; 40: 388-393. Ref.: https://goo.gl/yOfkRf

16. Nair MK, Lakshmi MA, Latha S, Lakshmi G, Harikumaran Nair GS, et al. CDC Kerala 15: Developmental Evaluation Clinic (2-10 yr.)-developmental diagnosis and use of home intervention package. Indian J Pediatr. 2014; 81: 142-150. Ref.: https://goo.gl/OiBUF7

17. Tsai JT, Kuo HT, Chou IC, Tsai MY, Tsai CH. A clinical analysis of children with developmental delay. Acta Paediatr Taiwan. 2005; 46: 192-195. Ref.: https://goo.gl/SRjpOU

18. Shevell M, Majnemer A, Rosenbaum P, Abrahamowicz M. Profile of referrals for early childhood developmental delay to ambulatory subspecialty clinics. J Child Neurol. 2001a; 16: 645-650. Ref.: https://goo.gl/szojXa

19. Lawrence R, Bateman N. 12 minute consultation: An evidence-based approach to the management of a child with speech and language delay. Clin Otolaryngol. 2013; 38: 148-153. Ref.: https://goo.gl/QEW74n

20. Chin RY, Moran T, Fenton JE. The otological manifestations associated with autistic spectrum disorders. Int J Pediatr Otorhinolaryngol. 2013; 77: 629-634. Ref.: https://goo.gl/m32Un0

21. Craig F, Lamanna AL, Margari F, Matera E, Simone M, et al. Overlap between Autism Spectrum Disorders and Attention Deficit Hyperactivity Disorder: Searching for Distinctive/Common Clinical Features. Autism Res. 2015; 8: 328-337. Ref.: https://goo.gl/j6okKR

22. Andersson GW, Miniscalco C, Gillberg C. Preschoolers assessed for autism: parent and teacher experiences of the diagnostic process. Res Dev Disabil. 2014; 35: 3392-3402. Ref.: https://goo.gl/9HBnbn

23. Orinstein AJ, Helt M, Troyb E, Tyson KE, Barton ML, et al. Intervention for optimal outcome in children and adolescents with a history of autism. J Dev Behav Pediatr. 2014; 35: 247-256. Ref.: https://goo.gl/Onn1UL

24. Moilanen I, Mattila ML, Loukusa S, Kielinen M. [Autism spectrum disorders in children and adolescents]. Duodecim. 2012; 128: 1453-62. Ref.: https://goo.gl/wJD5w5

25. Dykens EM, Fisher MH, Taylor JL, Lambert W, Miodrag N. Reducing distress in mothers of children with autism and other disabilities: a randomized trial. Pediatrics. 2014; 134: 454-463. Ref.: https://goo.gl/gHUPg6

26. Singh z AK, Kumar R, Mishra CK, Khera A, Srivastava A. Moving from Survival to Healthy Survival through Child Health Screening and Early Intervention Services Under Rashtriya Bal Swasthya Karyakram (RBSK). Indian J Pediatr. 2015; 82: 1012-1018. Ref.: https://goo.gl/KofNwf

27. Abrahamsson A, Samarasinghe K. Open pre-schools at integrated health services-A program theory. Int J Integr Care. 2013; 13: Ref.: https://goo.gl/yMFTQF

28. Lagström H, Rautava $P$, Kaljonen A, Räihä $H$, Pihlaja $P$, et al. Cohort profile: Steps to the healthy development and well-being of children (the STEPS Study). Int J Epidemiol. 2013; 42: 1273-1284. Ref.: https://goo.gl/qrnjCl 
29. Department of Health. Improving Chronic Disease Management. 2004.

30. Stuart K. Leading multi-professional teams in the children's workforce: an action research project. Int J Integr Care. 2012; 12: Ref.: https://goo.gl/urxqGt

31. Rosenberg RE, Ardalan K, Wong W, Patel S, Gold-von Simson G, et al. Postoperative spinal fusion care in pediatric patients: Co-management decreases length of stay. Bull Hosp Jt Dis. (2013). 2014; 72: 197-203. Ref.: https://goo.gl/XOyKTb

32. Wainwright MS, Grimason M, Goldstein J. Smith CM, Amlie-Lefond C, et al. Building a pediatric neurocritical care program: a multidisciplinary approach to clinical practice and education from the intensive care unit to the outpatient clinic. Semin Pediatr Neurol. 2014; 21: 248-254. Ref.: https://goo.gl/y8hmCp

33. Vowinkel T, Laukoetter M, Mennigen R, Hahnenkamp K, Gottschalk A, et al. A two-step multidisciplinary approach to treat recurrent esophageal strictures in children with epidermolysis bullosa dystrophica. Endoscopy. 2015; 47: 541-544. Ref.: https://goo.gl/NE8vIW

34. Fuengfoo A, Sakulnoom K. Clinical abnormalities, early intervention program of Down syndrome children: Queen Sirikit National Institute of Child Health experience. J Med Assoc Thai. 2014; 97 152-158. Ref.: https://goo.gl/BozFkR

35. Bell A, Corfield M, Davies J, Richardson N. Collaborative Trans disciplinary intervention in early years putting theory into practice. Child Care Health Dev. 2010; 36: 142-148. Ref.: https://goo.gl/MMmn1X

36. Oosterling IJ, Wensing M, Swinkels SH, van der Gaag RJ, Visser JC, et al. advancing early detection of autism spectrum disorder by applying an integrated two-stage screening approach. J Child Psychol Psychiatry. 2010; 51: 250-258. Ref.: https://goo.gl/4uaOM2

37. Charman T, Baird G. Practitioner review: Diagnosis of autism spectrum disorder in 2- and 3-year-old children. J Child Psychol Psychiatry. 2002; 43: 289-305. Ref.: https://goo.gl/fpONZD

38. Bent CA, Dissanayake C, Barbaro J. Mapping the diagnosis of autism spectrum disorders in children aged under 7 years in Australia.2010-2012, Med J Aust. 2015; 202: 317-320. Ref.: https://goo.gl/Pt1Bj2

39. Shevell M, Ashwal S, Donley D, Flint J, Gingold M, et al. Practice parameter. Evaluation of the child with global developmental delay. Report of the Quality Standards Subcommittee of the American Academy of Neurology and the Practice Committee of the Child Neurology Society. Neurology. 2003; 60: 367-380. Ref.: https://goo.gl/7evlXm

40. Bailey DB Jr, Skinner D, Sparkman KL. Discovering fragile $X$ syndrome: family experiences and perceptions. Pediatrics. 2003; 111: 407-416. Ref.: https://goo.gl/7qSTQ9

41. Shevell MI, Majnemer A, Rosenbaum $P$, Abrahamowicz M. Etiologic determination of childhood developmental delay. Brain Dev. 2001b; 23: 228-235. Ref.: https://goo.gl/aFB8qw

42. Guinchat V, Cravero C, Diaz L, Périsse D, Xavier J, et al. Acute behavioral crises in psychiatric inpatients with autism spectrum disorder (ASD): recognition of concomitant medical or non-ASD psychiatric conditions predicts enhanced improvement. Res Dev Disabil. 2015; 38: 242-255. Ref.: https://goo.gl/n09UBf

43. Parry TS. Assessment of developmental learning and behavioural problems in children and young people. Med J Aust. 2005; 183: 43-48. Ref.: https://goo.gl/n5zB8a

44. Fernell E, Norrelgen F, Bozkurt I, Hellberg G, Löwing K. Developmental profiles and auditory perception in 25 children attending special preschools for language-impaired children. Acta Paediatr. 2002; 91: 1108-1115. Ref.: https://goo.gl/OQDBKY

45. Trabacca A, Vespino T, Di Liddo A, Russo L. Multidisciplinary rehabilitation for patients with cerebra palsy: improving long-term care. J Multidiscip Healthc. 2016; 9: 455-462. Ref.: https://goo.gl/ZvTBLQ

46. Bakheit AM, Bower E, Cosgrove A, Fox M, Morton R, et al. Opinion statement on the minimal acceptable standards of healthcare in cerebral palsy. Disabil Rehabil. 2001; 23: 578-582. Ref.: https://goo.gl/h0jZiF

47. Fitzgerald A, Bailey M, Smith AC, Webb K, Keating D, et al. Child development services: a multidisciplinary approach to professional education via videoconference. J Telemed Telecare. 2002; 8: 19-21. Ref.: https://goo.gl/V5NWTT

48. Chan DS, Callahan CW, Moreno C. Multidisciplinary education and management program for children with asthma. Am J Health Syst Pharm. 2001; 58: 1413-1417. Ref.: https://goo.gl/nSxRSS

49. O'Shea TM, Nageswaran S, Hiatt DC, Legault C, Moore ML, et al. Follow-up care for infants with chronic lung disease: a randomized comparison of community- and center-based models. Pediatrics. 2007; 119: 947-957. Ref.: https://goo.gl/jrVFiH 
50. lannaccone ST. Modern management of spinal muscular atrophy. J Child Neurol. 2007; 22: 974-978. Ref.: https://goo.gl/GyTfnC

51. Acerini CL, Tasker RC. Traumatic brain injury induced hypothalamic-pituitary dysfunction: a paediatric perspective. Pituitary. 2007; 10: 373-380. Ref.: https://goo.gl/uiNLXI

52. Goldstein J, Plioplys S, Zelko F, Mass S, Corns C, et al. Multidisciplinary approach to childhood epilepsy: exploring the scientific rationale and practical aspects of implementation. J Child Neurol. 2004; 19: 362-378. Ref.: https://goo.gl/oqDK07

53. Kelishadi R, Azizi-Soleiman F. Controlling childhood obesity. A systematic review on strategies and challenges. J Res Med Sci. 2014; 19: 993-1008. Ref.: https://goo.gl/w5nP8t

54. Sothern M, Udall JN Jr, Suskind RM, Vargas A, Blecker U. Weight loss and growth velocity in obese children after very low calorie diet, exercise and behavior modification. Acta Paediatr. 2000; 89: 1036-1043. Ref.: https://goo.gl/dr6Tm1

55. Mc Donagh JE, Kelly DA. Transitioning care of the pediatric recipient to adult caregivers. Pediatr Clin North Am. 2003; 50: 1561-1583. Ref.: https://goo.gl/7wp4Fa

56. Guy J, Persaud J, Davies E, Harvey D. Drug errors. what role do nurses and pharmacists have in minimizing the risk? J Child Health Care. 2003; 7: 277-290. Ref.: https://goo.gl/fmxd86

57. Giancotti A, Romanini G, Docimo R, Arcuri C. Clinical treatment of oral manifestations of BeckwithWiedeman syndrome in a child. J Clin Pediatr Dent. 2003; 27: 377-380. Ref.: https://goo.gl/ythBKq

58. Petrini P. Treatment strategies in children with hemophilia. Paediatr Drugs. 2002; 4: 427-437. Ref.: https://goo.gl/3VfQpK

59. Ebeling $H$, Tapanainen $P$, Joutsenoja $A$, Koskinen $M$, Morin-Papunen $L$, et al. A practice guideline for treatment of eating disorders in children and adolescents. Ann Med. 2003; 35: 488-501. Ref.: https://goo.gl/W5IRMe

60. Baker SR, Owens J, Stern M, Willmot D. Coping strategies and social support in the family impact of cleft lip and palate and parents' adjustment and psychological distress. Cleft Palate Craniofac J. 2009; 46: 229-236. Ref.: https://goo.gl/kA40sk

61. Webb AA, Watts R, Read-Ward E, Hodgkins J, Markus AF. Audit of a multidisciplinary approach to the care of children with unilateral and bilateral cleft lip and palate. Br J Oral Maxillofac Surg. 2001; 39: 182-188. Ref.: https://goo.gl/JdQL8d

62. Fishman G, Fliss DM, Benjamin S, Margalit N, Gil Z, et al. Multidisciplinary surgical approach for cerebrospinal fluid leak in children with complex head trauma. Childs Nerve Syst. 2009; 25: 915-923. Ref.: https://goo.gl/TZUm8M

63. Van Kuyk EM, Brugman-Boezeman AT, Wissink-Essink M, Severijnen RS, Festen C, et al. Defecation problems in children with Hirschsprung's disease: a bio psychosocial approach. Pediatr Surg Int. 2000; 16: 312-316. Ref.: https://goo.gl/0sGxAR

64. Bloemen MA, Verschuren O, van Mechelen C, Borst HE, de Leeuw AJ, et al. Personal and environmental factors to consider when aiming to improve participation in physical activity in children with Spina Bifida: a qualitative study. BMC Neurol. 2015; 15: 11. Ref.: https://goo.gl/LXUhdX

65. Marini D, Agnoletti G. Interventional treatment of congenital heart disease patients. Minerva Cardioangiol. 2010; 58: 79-96. Ref.: https://goo.gl/OY3lt0

66. Rubin JJ. Psychosomatic pain. New insights and management strategies. South Med J. 2005; 98: 1099-1110. Ref.: https://goo.gl/MwwZoL

67. Anthony KK, Schanberg LE. Juvenile primary fibromyalgia syndrome. Curr Rheumatol Rep. 2001; 3: 165-171. Ref.: https://goo.gl/QkIRe2

68. Sharma ST, Nieman LK, Feelders RA. Cushing's syndrome. Epidemiology and developments in disease management. Clin Epidemiol. 2015; 7: 281-293. Ref.: https://goo.gl/ds8Ce1

69. Department for Children School and families (DCSF) Leading and managing children's services in England a national professional development framework. London: DCSF; 2008. 